Research Article

\title{
Effect of Cyclic Cryogenic Treatment on Wear Resistance, Impact Toughness, and Microstructure of 42CrMo Steel and Its Optimization
}

\author{
Haidong Zhang $\mathbb{D}^{\mathbb{D}}$, Xianguo Yan $\mathbb{D}$, Qiang Hou, and Zhi Chen \\ School of Mechanical Engineering, Taiyuan University of Science and Technology, Taiyuan 030024, China \\ Correspondence should be addressed to Xianguo Yan; yan_xg2008@126.com
}

Received 29 September 2020; Revised 8 December 2020; Accepted 30 December 2020; Published 12 January 2021

Academic Editor: Patrice Berthod

Copyright (c) 2021 Haidong Zhang et al. This is an open access article distributed under the Creative Commons Attribution License, which permits unrestricted use, distribution, and reproduction in any medium, provided the original work is properly cited.

\begin{abstract}
Cyclic cryogenic treatment, a major cycle accompanied by zero or more subsidiary cycles, was conducted on the hardened $42 \mathrm{CrMo}$ steel using orthogonal design method to investigate the effect of different parameters (cryogenic temperature, holding time, and cycles number) of cryogenic treatment on wear resistance and impact toughness of the steel. Range analysis was performed to obtain the influencing order of the three parameters and their optimum values. The results show that after cryogenic treatment, the steel exhibits higher wear resistance and impact toughness, whereas no significant change in hardness. For wear resistance, the influencing order of parameters is cryogenic temperature, holding time, and cycles number, and the optimum values of the parameters are $-160^{\circ} \mathrm{C}, 24 \mathrm{~h}$ and two cycles, respectively. For impact toughness, the influencing order of parameters is cryogenic temperature, cycles number, and holding time, and the optimum values are $-120^{\circ} \mathrm{C}, 24 \mathrm{~h}$ and three cycles, respectively. The wear topography and fracture topography were examined using scanning electronic microscopy (SEM) to investigate the wear mechanism and fracture mechanism of the steel after cryogenic treatment, respectively. The results show that after cryogenic treatment, the wear mechanism is the combination of abrasive wear and adhesive wear with oxidative wear, and the fracture mechanism is a quasicleavage fracture. The microstructure was also examined by SEM to investigate the influencing mechanism of cryogenic treatment for improving wear resistance and impact toughness of the steel. It suggests that more precipitation of fine carbides dispersively distributed in the matrix is responsible for the beneficial effect of cryogenic treatment on wear resistance and impact toughness of the steel.
\end{abstract}

\section{Introduction}

As a type of medium carbon low-alloy structural steel, 42CrMo steel (approximately equivalent to AISI/SAE 4140 steel [1]) has high strength, ductility, and hardenability, coupled with good toughness, impact strength, repeated impact resistance, and fatigue resistance after proper quenching and tempering. For its good combination of mechanical properties and relatively low cost, the steel is extensively used in the manufacturing of conical pick bodies in the mining industry in China, as well as important parts and components in the machinery manufacturing industry, such as gears, shafts, high strength bolts, and so on [2]. In these applications, although the steel can obtain necessary mechanical properties by proper heat treatment, there is still a need for improving its mechanical properties to further enhance performance and prolong its service life.

Cryogenic treatment (CT), also called cryogenic processing, is generally regarded to be supplementary to conventional heat treatment [3], which is performed after quenching and usually before tempering or sometimes after tempering [4]. The purpose of applying cryogenic treatment is to improve some mechanical properties of materials by changing microstructure so as to enhance service performance or extend the service life of tools or parts [5]. In cryogenic treatment, materials are cooled down to a cryogenic temperature usually below $-80^{\circ} \mathrm{C}$, then held at the temperature for hours or days, and finally warmed up to 
ambient temperature [6]. Liquid nitrogen is usually used as a refrigerant agent because of its extremely low boiling point, inertness, and low cost, and accordingly, the cryogenic temperature can be as low as $-196^{\circ} \mathrm{C}$ [7]. This technology has been widely studied on a broad range of materials by numerous researchers in recent years, such as various steels [8-10], nonferrous alloys [11, 12], metallic glass [13], polymers [14], etc. Considerable research has demonstrated that cryogenic treatment can improve mechanical properties of steels, such as hardness [15], wear resistance [9, 16], toughness $[17,18]$, or relieving residual stress [19]. Therefore, it has been proved to be an effective and promising technology to improve certain mechanical properties of steel. In addition, as green manufacturing technology, it has a good application prospect in manufacturing industries.

Apparently, there are mainly four parameters involved in cryogenic treatment, which are cooling rate, cryogenic temperature, holding time, and warming rate. Cooling rate and warming rate are commonly controlled at a low value to avoid the thermal shock that may result in cracks in steels. Cryogenic temperature or holding time with different values is mostly considered in the cryogenic treatment of steel in literature. Menderes et al. [20] investigated the effect of cryogenic treatment for different holding times $(12 \mathrm{~h}, 24 \mathrm{~h}$, $36 \mathrm{~h}$, and $48 \mathrm{~h}$ ) at $-140^{\circ} \mathrm{C}$ on mechanical properties of AISI 4140 steel and found that tensile strength improved by $10 \%$ and hardness by $5 \%$ after cryogenic treatment and the optimum holding time of cryogenic treatment was $36 \mathrm{~h}$. Senthilkumar et al. [21-23] found that cryogenic treatment improved hardness and wear resistance of AISI 4140 steel as well as compressive residual stress, and wear resistance of the steel improved more after cryogenic treatment at $-196^{\circ} \mathrm{C}$ for $24 \mathrm{~h}$ than for $12 \mathrm{~h}$ and $18 \mathrm{~h}$. HÖKE et al. [24] reported that SAE 4140 steel had an improvement in microhardness and toughness after cryogenic treatment at $-140^{\circ} \mathrm{C}$ for $24 \mathrm{~h}$. Sahin et al. [25] studied the effect of different cryogenic temperatures $\left(-140^{\circ} \mathrm{C}\right.$ and $\left.-196^{\circ} \mathrm{C}\right)$ for $24 \mathrm{~h}$ on SAE 4140 steel and found that hardness slightly increased, which was attributed to the transformation of retained austenite to martensite. Jamali et al. [26] showed that cryogenic treatment could increase hardness, tensile strength, and impact toughness of AISI 4140 steel, and transformation of retained austenite to martensite and carbide precipitations were responsible for the improvement.

However, research on the effect of cryogenic treatment of $42 \mathrm{CrMo}$ or 4140 steel is limited and confined to either cryogenic temperature or holding time individually instead of both parameters together. Besides, only one cycle of cryogenic treatment was concerned in these studies. In this work, cyclic cryogenic treatment with different cryogenic temperatures, holding time, and cycles number fully considered was studied using orthogonal design method to investigate their effect on hardness, wear resistance, and impact toughness of $42 \mathrm{CrMo}$ steel. Range analysis was done to get the influencing order and optimum values of these parameters for improving wear resistance and impact toughness. In addition, microstructure, wear topography, and fracture topography were examined by SEM to investigate the influencing mechanism of cryogenic treatment on the steel.

\section{Materials and Methods}

2.1. Preparation of Materials. The raw material used in the experiments was a commercial bar of 42CrMo steel, which contains medium carbon content and low content of chromium, molybdenum, and manganese composition. Its chemical composition determined with a spark emission spectrometer (OBLF QSN 750-II) was listed in Table 1, according to GB/T 3077-2015 standard.

Specimens prepared from the steel bar were first hardened by austenitizing at $870^{\circ} \mathrm{C}$ for $20 \mathrm{~min}$ and quenching in oil. Then, the cyclic cryogenic treatment was performed on the hardened specimens in a program-controlled cryptoprocessor (FAWIP SLX-30), followed by tempering in a resistance box furnace (SX2-8-10). To be specific, every cycle of cryogenic treatment except the last one was followed by tempering at $150^{\circ} \mathrm{C}$ for $20 \mathrm{~min}$ to relieve thermal stress, whereas the last cycle was followed by tempering at $360^{\circ} \mathrm{C}$ for 2 hours to improve toughness. The details of cyclic cryogenic treatment with different parameters and their values were explained in the next subsection. The overall treatment process consisting of hardening, cyclic cryogenic treatment, and tempering is illustrated in Figure 1.

2.2. Cryogenic Treatment. Cryogenic treatment consists of the following parameters: cooling rate, cryogenic treatment or soaking temperature, holding time, warming rate, and cycles number. In this work, the cooling rate, along with the warming rate, was set at as low as $2^{\circ} \mathrm{C} / \mathrm{min}$ in order to prevent thermal shock from occurring in the specimens being treated. Taking cryogenic temperature, holding time, and cycles number as main influencing factors, cyclic cryogenic treatment was conducted by employing the orthogonal design method. Levels of each factor were selected equally as shown in Table 2, and therefore, the $\mathrm{L}_{9}\left(3^{4}\right)$ orthogonal array was utilized to design the experiment, ignoring interactions of the main factors, as shown in Table 3 . Each cycle of CT had the same cryogenic temperature, but the holding time of the first cycle (main cycle) was set as in Table 3, whereas that of the second and third cycles (subsidiary cycles) was set to $20 \mathrm{~min}$. The conventional heat treatment (CHT) was taken as the comparative one, which included no cryogenic treatment.

2.3. Mechanical Properties Test. After surfaces of each specimen were ground to remove the oxide layer resulting from heat treatment, hardness was measured on the Rockwell C scale with a Rockwell hardness tester (HR150A). At least five measurements for each specimen were carried out to get the average hardness.

Dry sliding wear test was run at room temperature using a multifunctional tribometer (Zhongke Kaihua CFT-I) configured with ball-on-disc components, as shown in Figure 2, where a ceramic ball $\left(\mathrm{Si}_{3} \mathrm{~N}_{4}\right)$ with a diameter of $5 \mathrm{~mm}$ was applied with a normal load of $60 \mathrm{~N}$ and slid at a radius of $8 \mathrm{~mm}$ against a specimen rotating at a speed of $300 \mathrm{rpm}$ for $90 \mathrm{~min}$. During sliding, the coefficient of friction 
TABLE 1: Chemical composition of raw 42CrMo steel.

\begin{tabular}{lcccccccccc}
\hline Element & $\mathrm{C}$ & $\mathrm{Cr}$ & $\mathrm{Mn}$ & $\mathrm{Si}$ & $\mathrm{Mo}$ & $\mathrm{Ni}$ & $\mathrm{Cu}$ & $\mathrm{S}$ & $\mathrm{P}$ & $\mathrm{Fe}$ \\
\hline Content/wt.\% & 0.4 & 0.99 & 0.63 & 0.21 & 0.19 & 0.0098 & 0.0088 & 0.0046 & 0.018 & Balanced \\
\hline
\end{tabular}

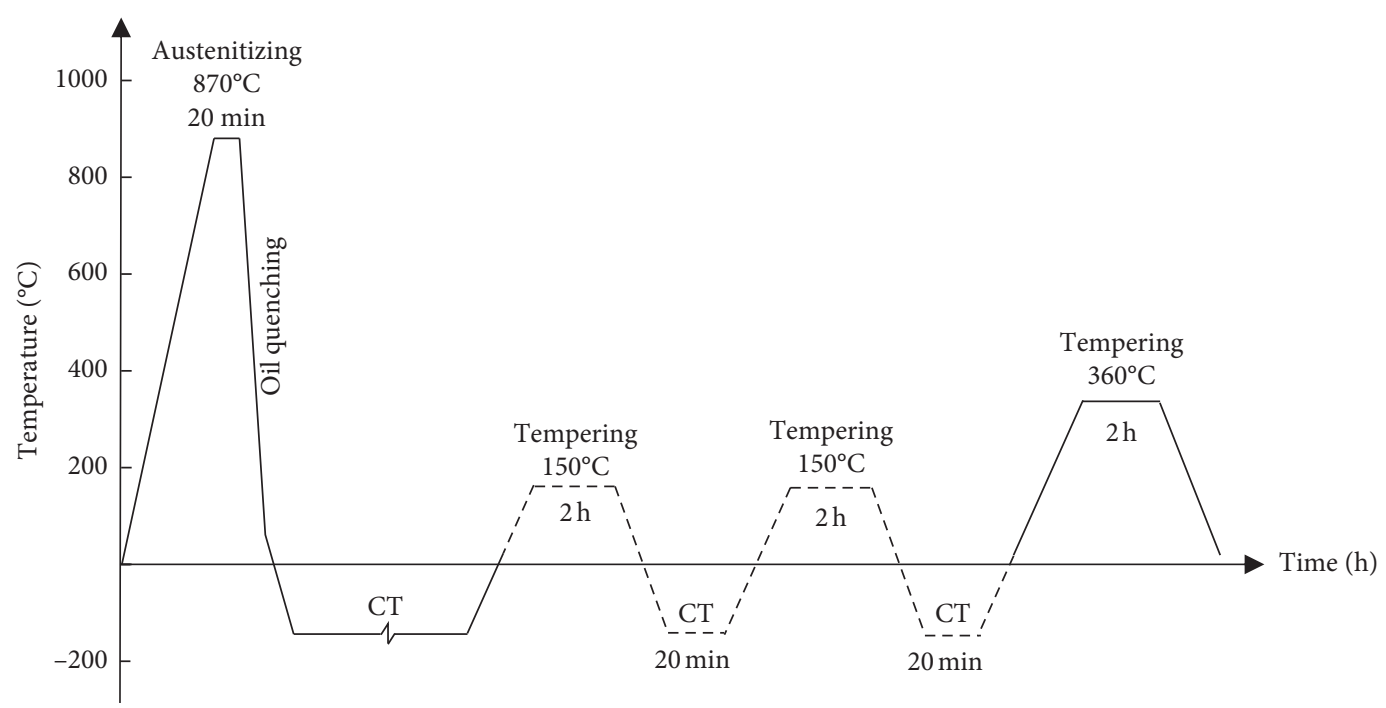

Figure 1: Schematic illustration of the treatment process of $42 \mathrm{CrMo}$ steel.

TABLE 2: Levels of factors in cryogenic treatment.

\begin{tabular}{lccc}
\hline & \multicolumn{3}{c}{ Levels } \\
Factors $(j)$ & 1 & 2 & 3 \\
\hline Cryogenic temperature $(\mathrm{A}) /{ }^{\circ} \mathrm{C}$ & -120 & -160 & -196 \\
Holding time $(\mathrm{B}) / \mathrm{h}$ & 2 & 12 & 24 \\
Cycles number $(\mathrm{C})$ & 1 & 2 & 3 \\
\hline
\end{tabular}

TABLE 3: The $\mathrm{L}_{9}\left(3^{4}\right)$ orthogonal array of cryogenic treatment.

\begin{tabular}{lccc}
\hline $\begin{array}{l}\text { Exp. } \\
\text { no. }\end{array}$ & $\begin{array}{c}\text { Cryogenic temperature/ } \\
\left({ }^{\circ} \mathrm{C}\right)\end{array}$ & $\begin{array}{c}\text { Holding time/ } \\
(\mathrm{h})\end{array}$ & $\begin{array}{c}\text { Cycles } \\
\text { number }\end{array}$ \\
\hline CT1 & -120 & 2 & 1 \\
CT2 & -120 & 12 & 2 \\
CT3 & -120 & 24 & 3 \\
CT4 & -160 & 2 & 2 \\
CT5 & -160 & 12 & 3 \\
CT6 & -160 & 24 & 1 \\
CT7 & -196 & 2 & 3 \\
CT8 & -196 & 12 & 1 \\
CT9 & -196 & 24 & 2 \\
\hline
\end{tabular}

(COF) was au tomatically measured in the step of $0.1 \mathrm{~s}$ by the tribometer.

Wear test specimens were cleaned with absolute ethanol and precisely weighed before and after the wear test on an analytical balance (BSM-220.4). Subsequently, wear mass loss $(\Delta m)$ was determined from the measured mass. Furthermore, wear rate was also calculated in terms of wear mass loss per sliding distance, and relative wear rate was calculated as the ratio of wear rate of CT to wear rate of CHT [27].

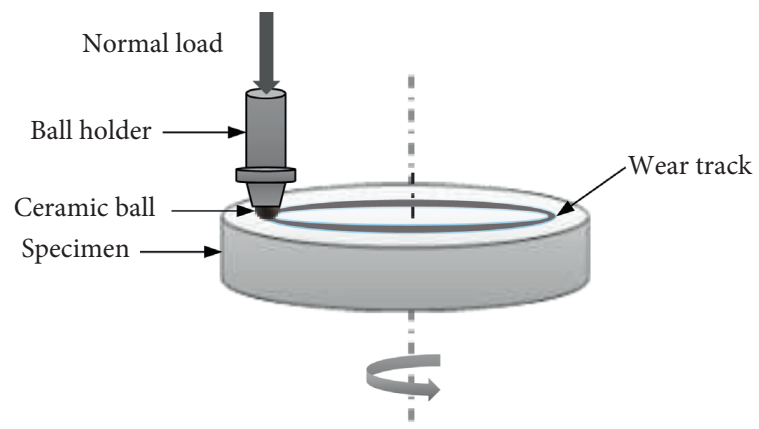

FIGURE 2: Schematic of the ball-on-disc wear test.

Charpy impact test was performed at room temperature to determine impact toughness with an impact testing machine (JB-300B) according to GB/T 229-2007 standard. Each impact specimen was in dimensions of $10 \mathrm{~mm} \times 10 \mathrm{~mm} \times 55 \mathrm{~mm}$ with a U-notch. The amount of energy absorbed $\left(A_{k}\right)$ by specimens was measured during fracture. For each experiment, three impact specimens were tested to obtain the average absorbed energy. The impact toughness was represented as the absorbed energy per unit of area of cross-section at the U-notch location, symbolized by $\alpha_{k}$.

2.4. Topography and Microstructure Characterization. Specimens without wear scar were prepared in size of $10 \mathrm{~mm} \times 10 \mathrm{~mm} \times 5 \mathrm{~mm}$ from the wear test specimens for microstructure test. Surfaces of the specimens were coarsely and finely ground with a succession of finer-grained metallographic abrasive papers, polished with $\mathrm{Cr}_{2} \mathrm{O}_{3}$ polishing power, and cleaned with acetone solution. Then the 
specimens were etched in $4 \%$ Nital solution, cleaned with distilled water and absolute ethanol, and blown dry. Immediately afterwards, SEM test was carried out in a scanning electron microscope (TESCAN VEGA3) to examine the microstructure. The number of precipitated carbides was analyzed on SEM micrographs using an image analysis software (ImageJ). Specimens with a piece of wear scar were prepared in dimensions of $10 \mathrm{~mm} \times 10 \mathrm{~mm} \times 5 \mathrm{~mm}$ from the wear test specimens for wear topography observation. The specimens were then cleaned with acetone solution and dried with a hair drier. Surface topography of wear scar was then observed with the SEM test apparatus to investigate the wear mechanism of CT specimens compared with CHT specimens. Fractography of fracture specimens prepared in the height of about $5 \mathrm{~mm}$ from impact specimens was observed by the SEM test apparatus at a magnification of $1000 \times$ so as to investigate the fracture mechanism influenced by cryogenic treatment. X-ray diffraction (XRD) analysis was performed on a polished hardened specimen in an XRD apparatus (Rigaku MiniFlex 600) with monochromatic $\mathrm{Cu}$ $\mathrm{K} \alpha$ radiation to identify phases of the steel after quenching.

\section{Results}

3.1. Hardness. The average hardness of specimens is illustrated in Figure 3. The result shows that the average hardness of specimens of CT has slight changes $(-1.7$ HRC to 1.8 HRC) compared with the specimen of CHT. However, seeing the errors of average hardness, hardness can be considered to have an insignificant change after cryogenic treatment.

3.2. Wear Resistance. Wear test results of CHT and CT specimens were listed in Table 4, where relative wear rates of CTs are less than 1 , showing that the wear rates of CT specimens are less than that of CHT specimen, which means that after cryogenic treatment, wear resistance of the steel improved.

Range analysis was performed from the wear test results to find the influencing order of the parameters of cryogenic treatment, along with the optimum parameters of cryogenic treatment. The results of the range analysis were shown in Table 5, where $\overline{K_{j m}}$ is the average of relative wear rates of factor $j$ at level $m$, and $R_{j}$ is the range of relative wear rate of factor $j$. Furthermore, the average relative wear rates calculated from the range analysis were plotted against cryogenic temperature, holding time, and cycles number, respectively, in Figure 4.

The rank order of factors in Table 5 suggests that the influencing order of the factors on decreasing wear rate is cryogenic temperature, holding time, and cycles number, which means the cryogenic temperature has the largest effect, and holding time has a medium effect, followed by cycles number with the least effect. The values of $\overline{K_{j m}}$ and the trends in Figure 4 indicate that the optimum parameters are $-160^{\circ} \mathrm{C}$ for cryogenic temperature, 24 hours for soaking time, and two cycles for cycles number.

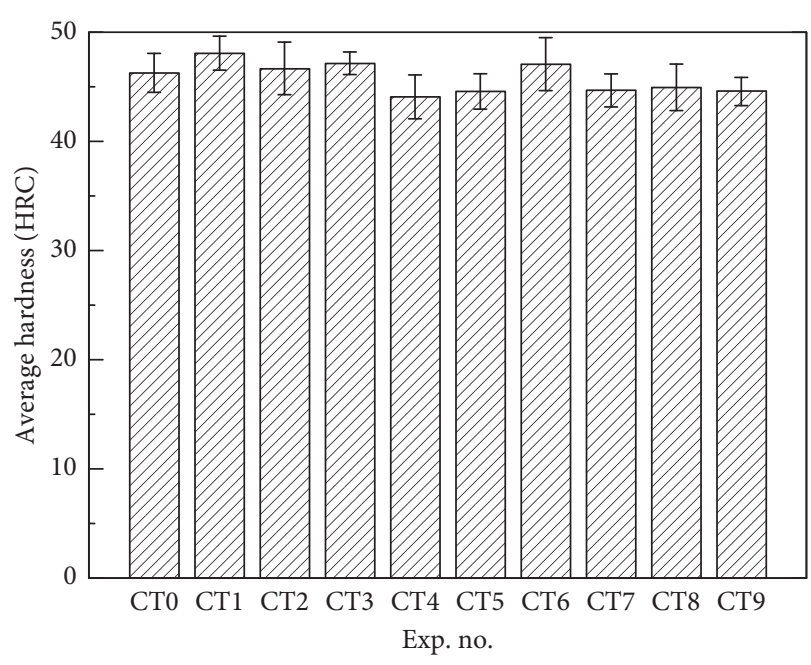

FIgURE 3: Average hardness with errors of specimens.

Figure 4 shows that the relative wear rate decreases more at $-160^{\circ} \mathrm{C}$ and $-196^{\circ} \mathrm{C}$ than that at $-120^{\circ} \mathrm{C}$, specifically by $13.46 \%$ and $13.17 \%$, respectively. Relative wear rate also decreases with extending holding time, and it obtains the maximum decrement of $12.81 \%$ when holding time is 24 hours. As for cycles number, the relative wear rate of two cycles of CT decreases by $11.16 \%$, more than that of one or three cycles. Figure 5 shows the relationship between average $\mathrm{COF}$ and wear mass loss. The average COF shares nearly the same change trend with the wear mass loss.

3.3. Impact Toughness. The impact toughness of specimens after the Charpy impact test was plotted in Figure 6. It shows that the impact toughness of CT specimens is higher than that of CHT, which indicates that after cryogenic treatment impact toughness of the steel improved.

In order to determine the rank order of cryogenic treatment parameters affecting impact toughness and to obtain the optimum values of the parameters, range analysis was performed. The results of range analysis of impact toughness were listed in Table 6 , where $\overline{K_{j m}}$ is mean of impact toughness of for factor $j$ at level $m$ and $R_{j}$ is the range of impact toughness for factor $j$. The effect trends of the major factors on impact toughness were illustrated in Figure 7.

The result of $\mathrm{B}>\mathrm{C}>\mathrm{A}$ indicates that the influencing order of the factors on improving impact toughness is as follows: holding time, cycles number, and cryogenic temperature. The optimum levels of $\mathrm{A}_{1} \mathrm{~B}_{3} \mathrm{C}_{3}$ indicate that for improving impact toughness, the optimum parameters of cryogenic treatment are $-120^{\circ} \mathrm{C}$ for cryogenic temperature, 24 hours for holding time, and three cycles for cycles number, with the corresponding improvement of impact toughness of $50.5 \%$.

3.4. Wear Topography. In view of the largest influence of cryogenic temperature on wear resistance, wear topography of CT specimens treated at different cryogenic temperature 
TABLE 4: Wear test results of CHT and CT specimens.

\begin{tabular}{lccc}
\hline Exp. no. & Wear loss $(\mathrm{mg})$ & Wear rate $\left(10^{-3} \mathrm{mg} \mathrm{m}^{-1}\right)$ & Relative wear rate $(\%)$ \\
\hline CHT & 46.3 & 34.1152 & 1.00 \\
CT1 & 43.6 & 32.1257 & 0.94 \\
CT2 & 45.7 & 33.6731 & 0.99 \\
CT3 & 42.6 & 31.3889 & 0.92 \\
CT4 & 40.4 & 29.7679 & 0.87 \\
CT5 & 38.6 & 28.4416 & 0.83 \\
CT6 & 41.2 & 30.3573 & 0.89 \\
CT7 & 43.2 & 31.8310 & 0.93 \\
CT8 & 40.1 & 29.5468 & 0.87 \\
CT9 & 37.3 & 27.4837 & 0.81 \\
\hline
\end{tabular}

TABLE 5: Range analysis results of relative wear rates.

\begin{tabular}{lccr}
\hline Factor $(j)$ & $\mathrm{A}$ & $\mathrm{B}$ & $\mathrm{C}$ \\
$\overline{\overline{K_{j 1}}}$ & 0.950 & 0.916 & 0.899 \\
$\overline{K_{j 2}}$ & 0.865 & 0.896 & 0.888 \\
$\overline{K_{j 3}}$ & 0.868 & 0.872 & 0.896 \\
Range $\left(R_{j}\right)$ & 0.084 & 0.044 & 0.011 \\
Rank order of factors & & $\mathrm{A}>\mathrm{B}>\mathrm{C}$ & $\mathrm{B}_{3}$ \\
Optimum levels & $\mathrm{A}_{2}$ & $\mathrm{C}_{2}$ \\
\hline
\end{tabular}

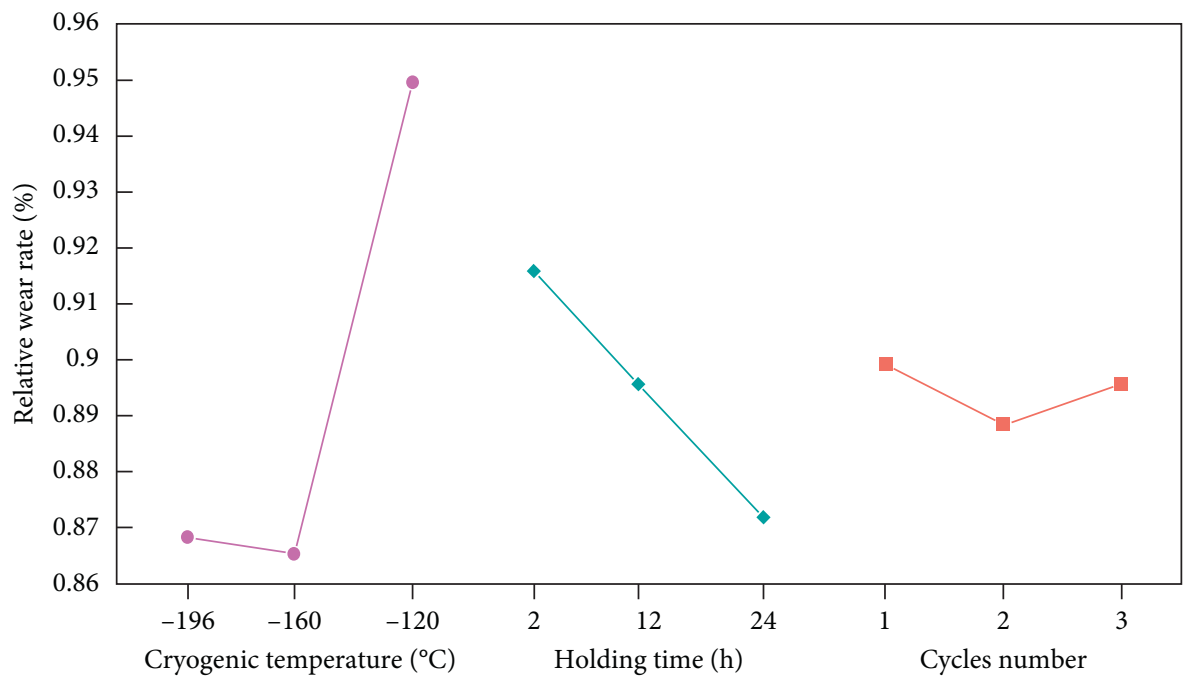

Figure 4: Relative wear rates against cryogenic temperature, holding time, and cycles number.

was examined. Considering that CT of $24 \mathrm{~h}$ has a greater impact on lowering wear rate than that of $12 \mathrm{~h}$ and $2 \mathrm{~h}$, specimens of CT3, CT6, and CT9 were taken to examine the wear topography at $-120^{\circ} \mathrm{C},-160^{\circ} \mathrm{C}$, and $-196^{\circ} \mathrm{C}$, respectively, neglecting the influence of cycles number because of its least effect. The SEM micrographs of worn surfaces of CHT and the selected CT specimens were shown in Figure 8.

It can be seen in Figure 8(a) that the worn surface of the CHT specimen is coarse with many craters, some of which have embedded particles, but little microcutting on it, indicating that the wear mechanism of CHT specimens is dominantly adhesive wear with insignificant abrasive wear. Instead, as shown in Figures 8(b)-8(d), the worn surfaces of
CT specimens are smooth with many craters and a few obvious microcuttings or ploughing grooves as well as plastic deformation, showing the occurrence of decreased adhesive wear and increased abrasive wear compared with that of CT specimen. In addition, there is also slight oxidation on the worn surfaces in Figures $8(b)-8(d)$. Thus, the wear mechanism of CT specimens is mainly abrasive wear and adhesive wear together with slight oxidative wear.

3.5. Fracture Topography. In consideration of the influencing order of the tree cryogenic treatment parameters, fracture topography of CT specimens treated for different 


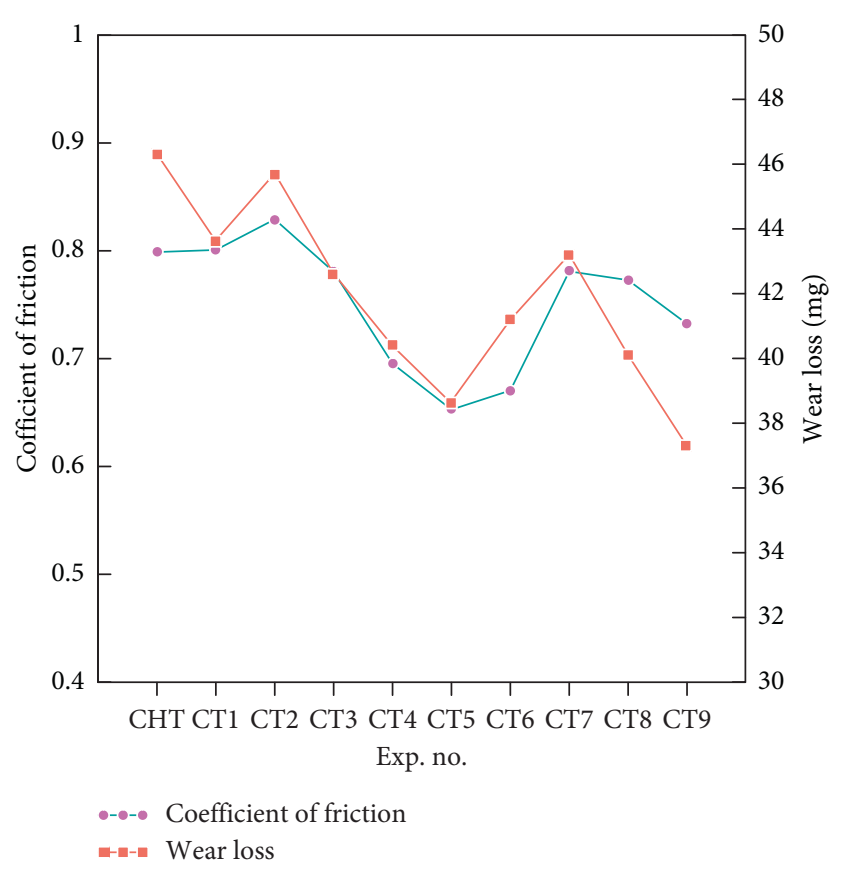

FIGURE 5: Comparison of average coefficient friction and wear mass loss of CHT and CTs.

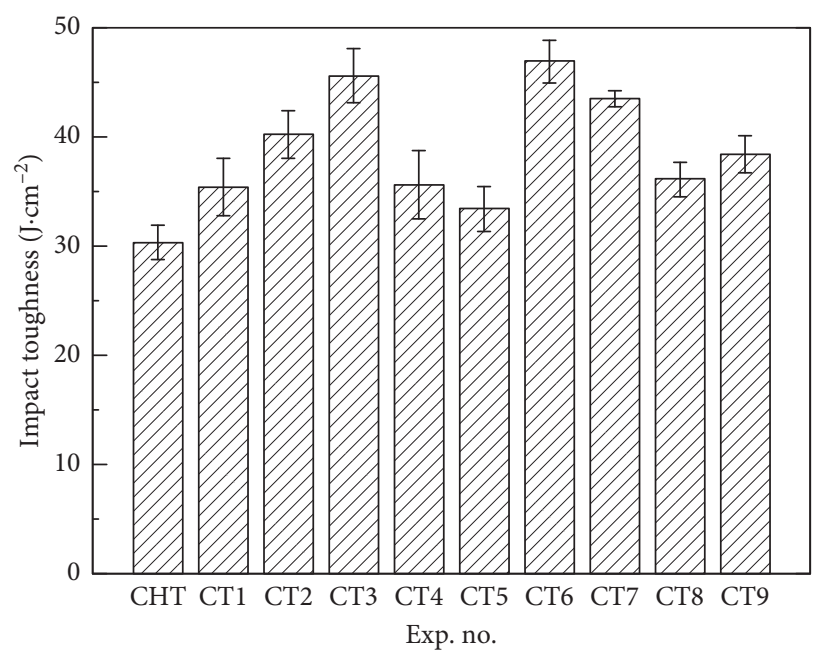

Figure 6: Impact toughness with errors of CHT and CT specimens.

TABLE 6: Range analysis results of impact toughness.

\begin{tabular}{lccc}
\hline Factor $(j)$ & $\mathrm{A}$ & $\mathrm{B}$ & $\mathrm{C}$ \\
$\overline{\overline{K_{j 1}}}$ & 40.4 & 38.2 & 39.5 \\
$\overline{K_{j 2}}$ & 38.6 & 36.6 & 38.1 \\
$\overline{K_{j 3}}$ & 39.3 & 43.6 & 40.8 \\
Range $\left(R_{j}\right)$ & 1.767 & 7.067 & 2.767 \\
Rank order of factors & & $\mathrm{B}>\mathrm{C}>\mathrm{A}$ & \\
Optimum levels & $\mathrm{A}_{1}$ & $\mathrm{~B}_{3}$ & $\mathrm{C}_{3}$ \\
\hline
\end{tabular}

holding times was focused on. Thus, CT7, CT5, and CT3 were taken to represent CTs for $2 \mathrm{~h}, 12 \mathrm{~h}$, and $24 \mathrm{~h}$, respectively, along with CHT as a comparison. The SEM micrographs of fracture surfaces of their specimens were shown in Figure 9. The fracture surfaces of all these specimens exhibit characteristics of cleavage facets and river patterns, accompanied by a small number of dimples and tear ridges, implying a typical quasicleavage fracture.

In Figures 9(b) and 9(d), cleavage facets become smaller, with shorter and more curved river pattern, and meanwhile tear ridges get more compared with those in Figures 9(a) and $9(c)$, meaning the characteristics of cleavage fracture decreases and the characteristics of quasicleavage fracture increases. That is why the impact toughness of CTs at $24 \mathrm{~h}$ and $2 \mathrm{~h}$ was much higher than that of CT for $12 \mathrm{~h}$ and CHT.

3.6. Microstructure Analysis. The microstructure of specimens of CHT and CTs at different cryogenic temperatures for $24 \mathrm{~h}$ and for different holding times at $-196^{\circ} \mathrm{C}$ was shown in Figures 10 and 11, respectively, and the corresponding quantitative analysis of precipitated carbides on the microstructure was illustrated in Figures 12 and 13, respectively. It can be seen in the micrographs that the microstructure of CHT and CT specimens both consists of dominant tempered troostite (dark areas) with fine particular carbides (white spots) distributed on the troostite matrix. But there are more carbides dispersively distributed on a matrix in CT specimens than in CHT specimens, indicating that cryogenic treatment can significantly promote fine carbide precipitation and dispersive distribution. Furthermore, as either lowering the cryogenic treatment or decreasing holding time, the number of carbides precipitated in the troostite matrix exhibits a roughly increasing trend, which indicates that both lowering cryogenic treatment and extending holding time are almost favorable to carbide precipitation. The XRD pattern of the hardened specimen was presented in Figure 14, where martensite $\left(\alpha^{\prime}\right)$ peaks indicate the predominant martensite phase of the steel after quenching, whereas no obvious austenite peak indicates the volume fraction of the undetected retained austenite is less than the detection limit of the XRD apparatus $(\sim 5 \%)[28]$.

\section{Discussion}

Extensive research has shown that the influencing mechanism of cryogenic treatment lies in microstructure changes induced by the cryogenic treatment that are mainly martensitic transformation of retained austenite and precipitation of carbides in the martensite matrix [29-31].

The effect of cryogenic treatment on the hardness of steels subjected to cryogenic treatment largely depends on the martensitic transformation of retained austenite but little on carbide precipitation [32-34]. So the transformation amount of retained austenite to martensite during cryogenic treatment determines the degree to which hardness can be improved. Specifically, the distinct presence of retained austenite after quenching in steels leads to a considerable transformation of austenite to martensite in cryogenic treatment, resulting in a significant increase in hardness, as shown in high speed steels with high carbon content $[35,36]$, 


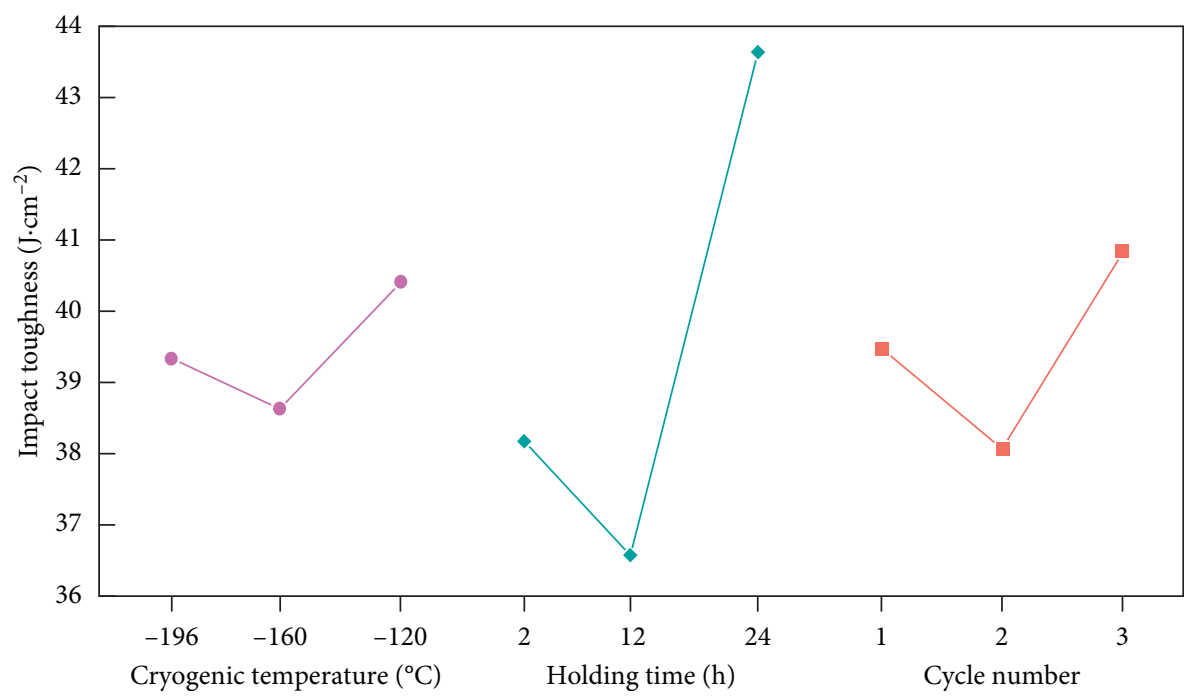

FIGURE 7: Impact toughness against cryogenic temperature, holding time, and cycles number.

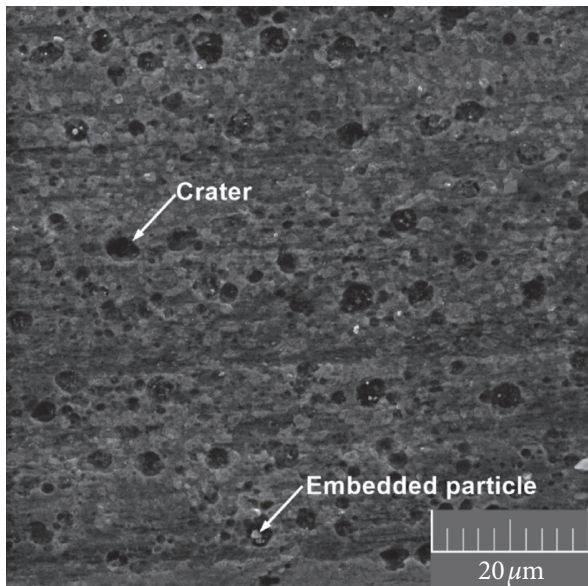

(a)

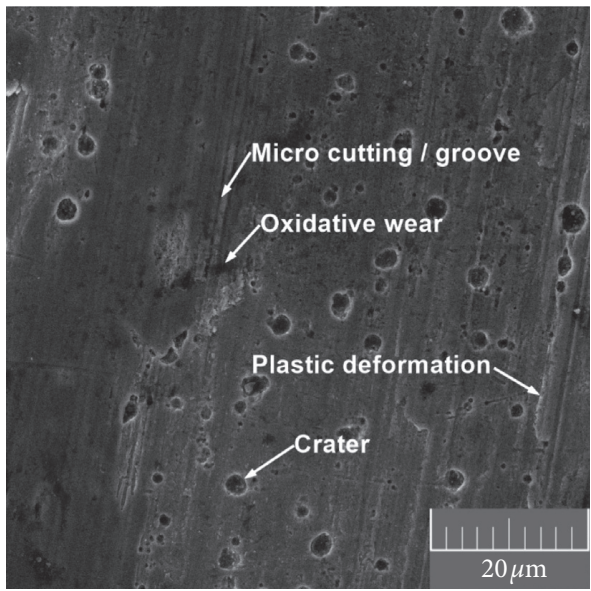

(c)

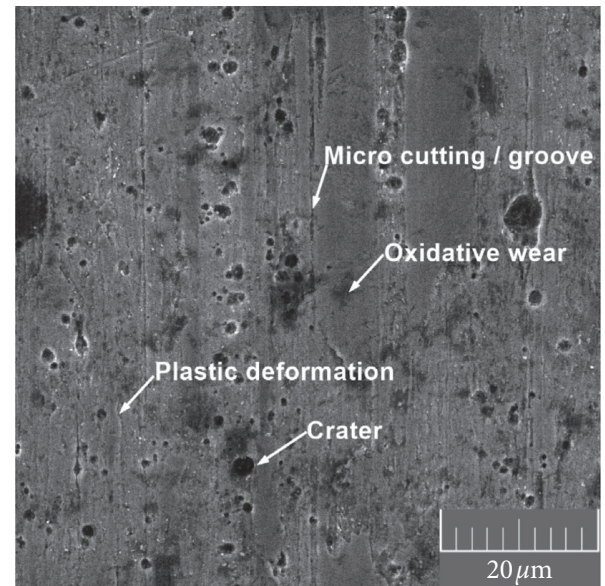

(b)

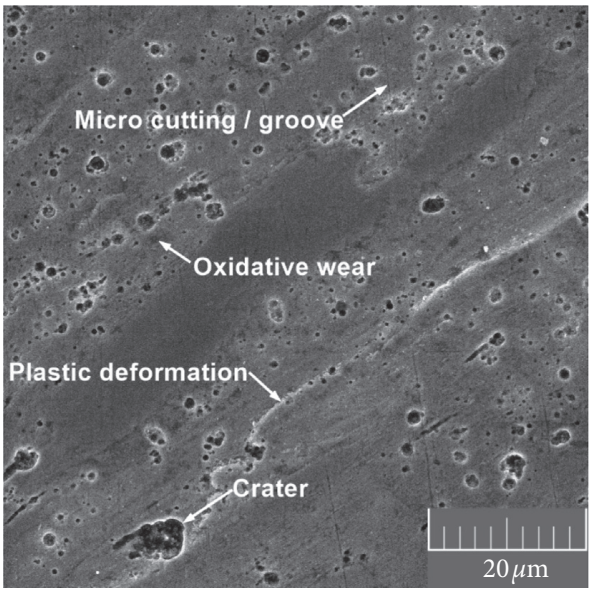

(d)

Figure 8: SEM micrographs of worn surfaces of (a) CHT specimens and CT specimens treated at (b) $-120^{\circ} \mathrm{C},(\mathrm{c})-160^{\circ} \mathrm{C}$, and $(\mathrm{d})-196^{\circ} \mathrm{C}$. 


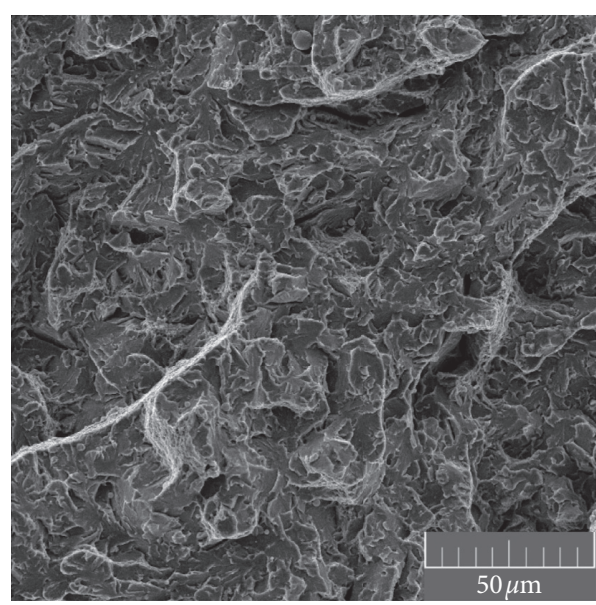

(a)

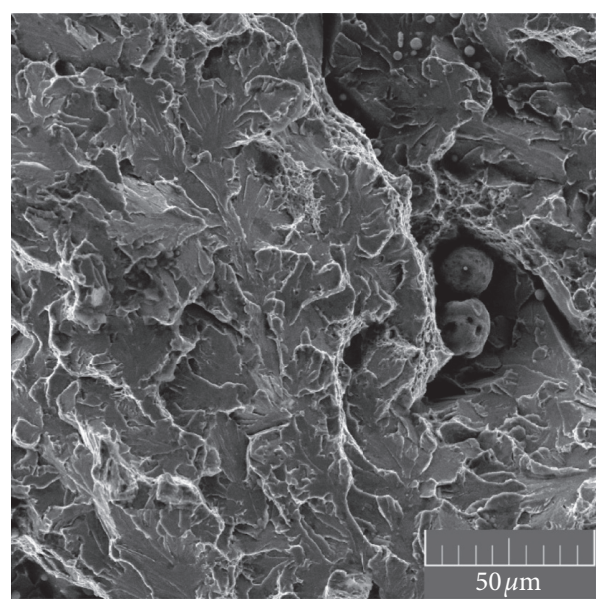

(c)

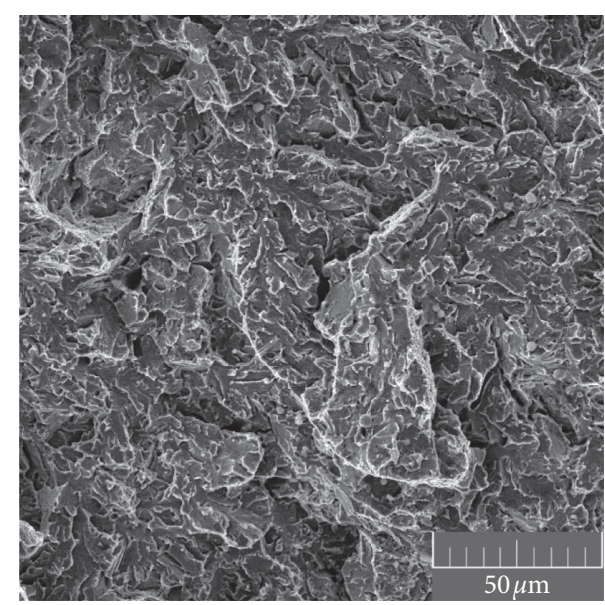

(b)

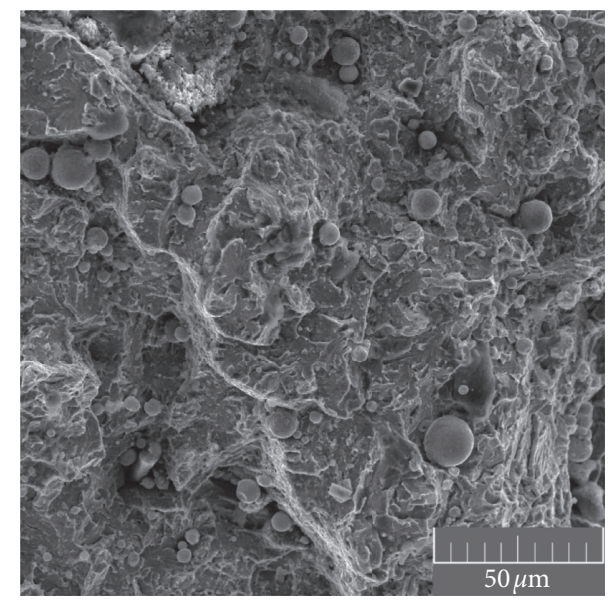

(d)

Figure 9: SEM micrographs of fracture surfaces of (a) CHT specimens and CT specimens treated for (b) $2 \mathrm{~h}$, (c) $12 \mathrm{~h}$, and (d) $24 \mathrm{~h}$.

whereas, in this work, a low amount of retained austenite after quenching of the steel as shown in the XRD analysis results and the findings of Zhao et al. [37], along with the incapability of complete transformation of retained austenite into martensite during cryogenic treatment $[22,34,38]$, may result in the limited change in hardness of the steel after cryogenic treatment. Notably, the lowered carbon content in martensite matrix because of more carbide precipitation in cryogenic treatment may adversely affect the hardness [39], which could offset the beneficial effect of martensitic transformation of retained austenite on hardness. Overall, the combination of these two contrary effects results in an insignificant change in hardness.

As suggested in this work, the cryogenic treatment can improve the wear resistance of the steel, which is consistent with the findings of the literature, but a different parameter of cryogenic treatment impacts to a different degree. Between the cryogenic temperature and holding time, the cryogenic temperature is the most influencing parameter, followed by holding time as the second influencing parameter, which agrees with the findings of Darwin et al. [40]. Many researchers have found that lowering cryogenic temperature could obtain more improvement in wear resistance of steels, and the optimum value of cryogenic temperature was $-196^{\circ} \mathrm{C}[9,25,41,42]$. Similarly but slightly different in this work, cryogenic treatment at $-160^{\circ} \mathrm{C} \mathrm{ob-}$ tained more improvement of wear resistance than $-120^{\circ} \mathrm{C}$, and wear resistance at $-196^{\circ} \mathrm{C}$ improved almost the same as $-160^{\circ} \mathrm{C}$, only higher by $0.29 \%$, which may be due to the introduction of multiple cycles of cryogenic treatment. Likewise, improvement of wear resistance increases with extending holding time, as reported in recent research [43-46], which was demonstrated in this work as well. And the optimum holding time was $24 \mathrm{~h}$ in this work, which was identical to the findings of Senthilkumar et al. [21]. But when holding time extends beyond the optimum value, further extending holding time will not continue to take effect. The optimum holding time changes with types of steels, substantially at $12 \mathrm{~h} \mathrm{[47],} \mathrm{even} 24 \mathrm{~h}$ [48], or $36 \mathrm{~h}$ [49]. Besides cryogenic temperature and holding time, cycles number, which was not involved in literature, to the author's knowledge, was demonstrated to be the third influencing parameter in this work, and the optimum value was two cycles, namely a major cycle followed by a subsidiary one.

In view of the limited transformation of retained austenite, the main reason that cryogenic treatment can 


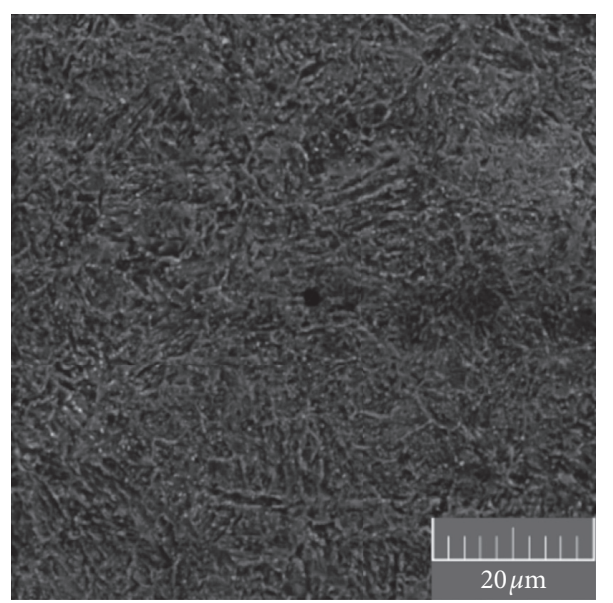

(a)

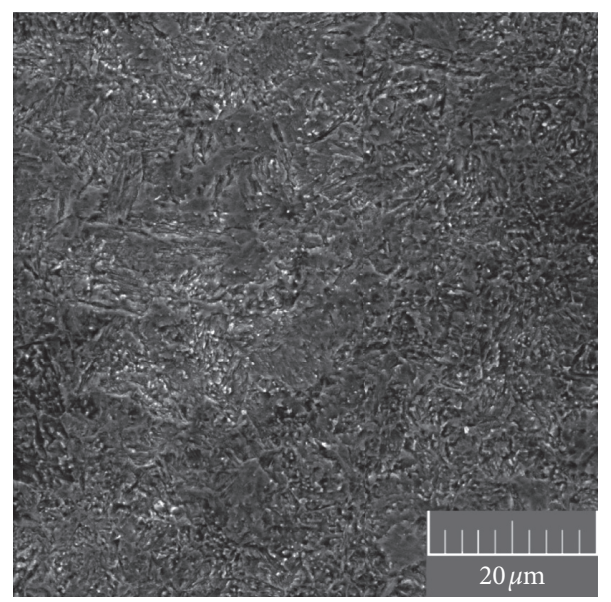

(c)

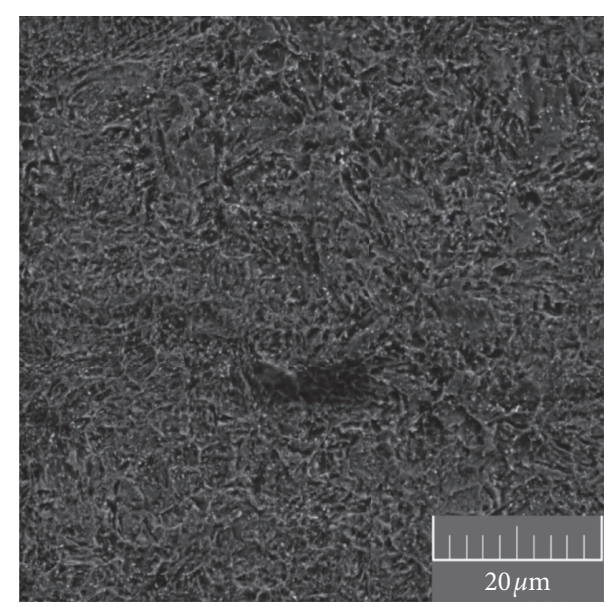

(b)

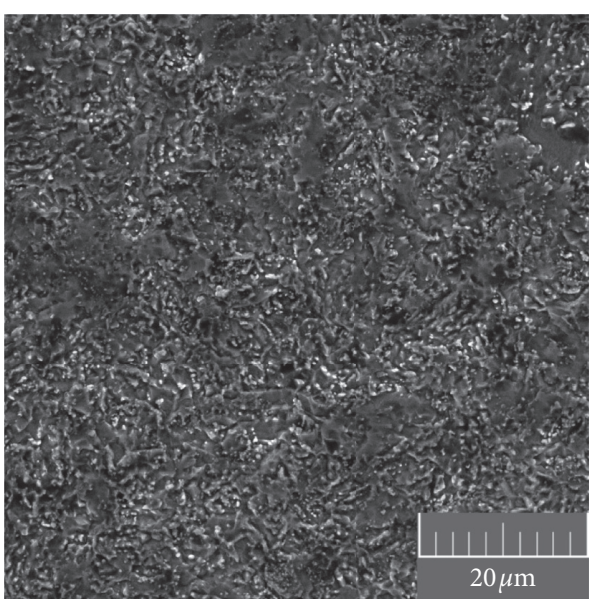

(d)

FIGURE 10: SEM micrographs of (a) CHT specimen and CT specimens treated at (b) $-120^{\circ} \mathrm{C}(\mathrm{CT} 3),(\mathrm{c})-160^{\circ} \mathrm{C}(\mathrm{CT} 6)$, and (d) $-196^{\circ} \mathrm{C}(\mathrm{CT} 9)$ for $24 \mathrm{~h}$.

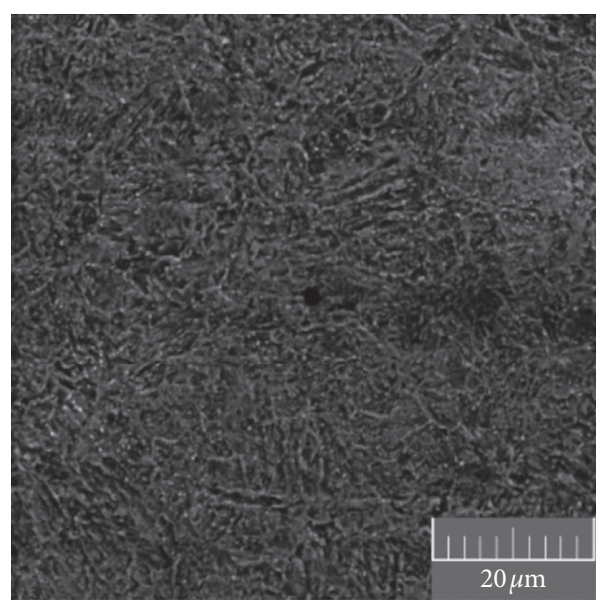

(a)

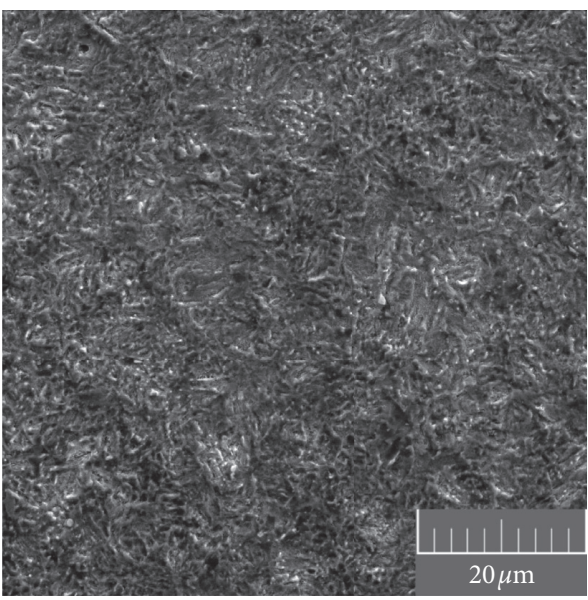

(b)

FIgURE 11: Continued. 


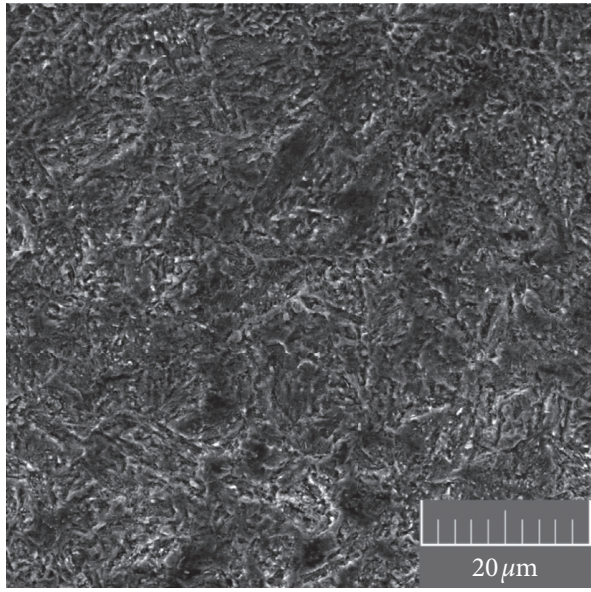

(c)

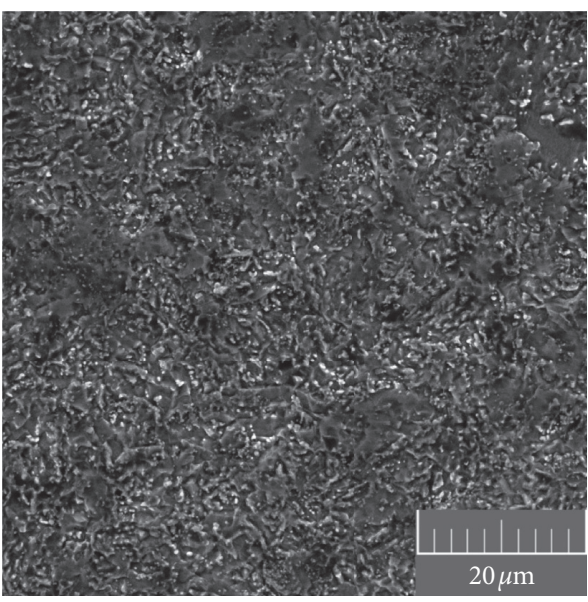

(d)

FIGURE 11: SEM micrographs of fracture surfaces of (a) CHT specimen and CT specimens treated for (b) $2 \mathrm{~h}$ (CT7), (c) 12h (CT8), and (d) $24 \mathrm{~h}$ (CT9) at $-196^{\circ} \mathrm{C}$.

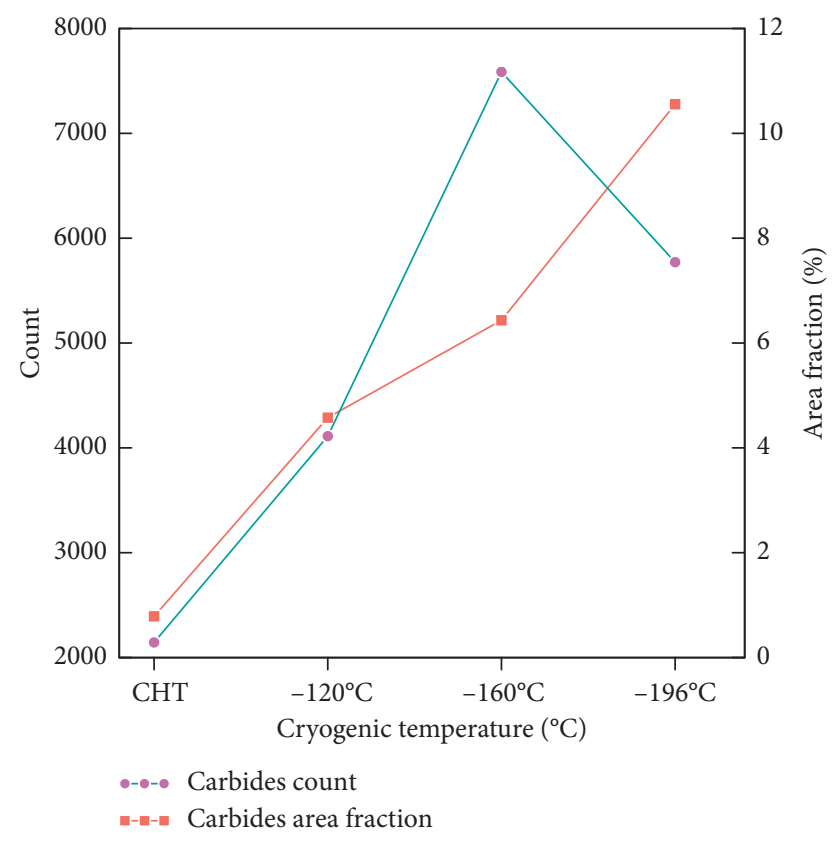

FIGURE 12: The number of precipitated carbides of CHT and CTs with different cryogenic temperatures.

improve wear resistance of the steel can be carbide precipitation, as shown by the microstructure test results in this work. Specifically, when the steel was cooling down the cryogenic temperature, the microstructure shrank causing more supersaturation of martensite in the microstructure [34]. Under shrinking strain energy, interstitial carbon atoms in the supersaturated martensite likely segregated to nearby dislocations, grain boundaries, or other crystal defects, forming carbon clusters $[50,51]$. In the subsequent tempering, because of temperature rising, carbon clusters grew up into nuclei and carbides precipitated at the nuclei from the supersaturated martensite [52-54], which

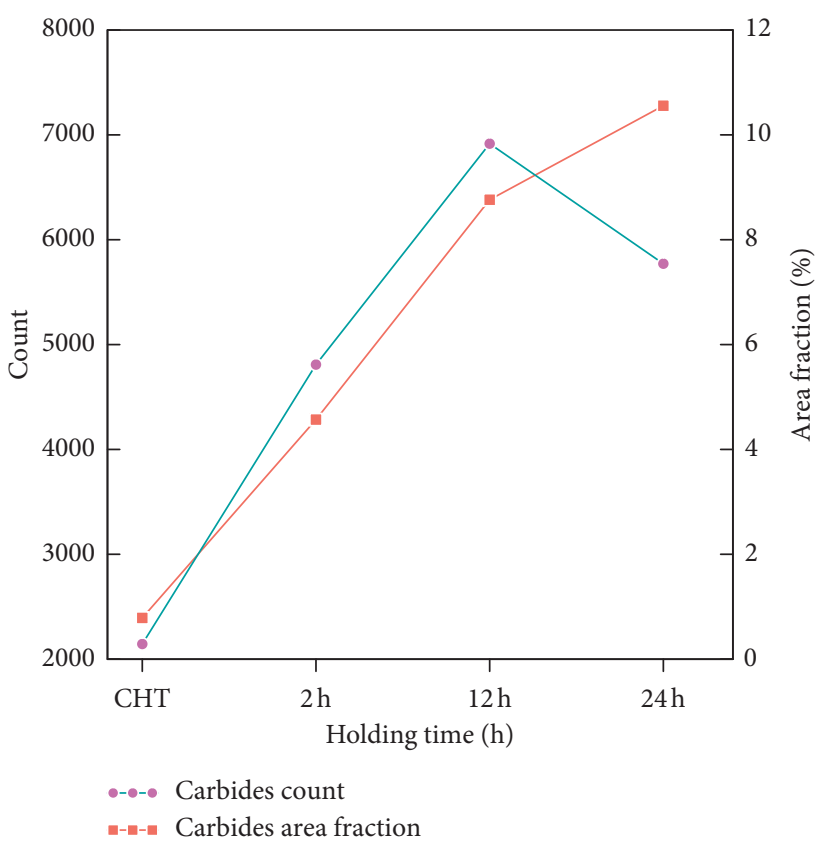

FIgURE 13: The number of precipitated carbides of CHT and CTs with different holding times.

meanwhile transformed into troostite. The hard carbides embedded in the matrix are beneficial to wear resistance, and the amount of the carbides, in addition to their fineness and distribution in the matrix, can significantly influence the wear resistance of the steel. So more precipitation of fine carbides induced by cryogenic treatment and dispersively distributed in the matrix of troostite finally results in the improvement of wear resistance of the steel. In addition, the fine carbides can reduce the adhesion friction in the steel/ ceramic friction pair as shown by the wear topography, 


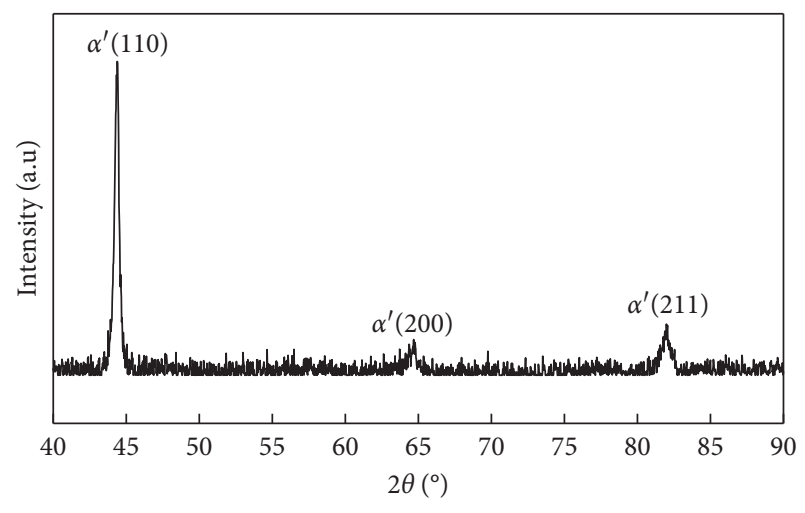

Figure 14: X-ray diffraction pattern of the hardened specimen of the steel.

which is advantageous to decrease in COF, and therefore more precipitated carbides promoted by cryogenic treatment can also improve COF of the steel.

Besides improving wear resistance, as demonstrated in this work, cryogenic treatment can also improve impact toughness of the steel, which is similar to findings in the literature $[55,56]$, where cryogenic treatment was conducted at constant cryogenic temperatures, such as $-180^{\circ} \mathrm{C}$ or $-196^{\circ} \mathrm{C}$. For holding time, $24 \mathrm{~h}$ has a better effect on improving impact toughness than $2 \mathrm{~h}$, which is in accordance with the findings of Israel et al. [55]. During tempering after cryogenic treatment of the steel, more precipitation of fine carbides leads to more reduction in carbon content in the matrix, making the matrix more ductile. In addition, dispersive distribution of fine particular carbides may reduce the adverse impact of carbides on the toughness of the matrix by weakening the formation and propagation of microcracks during fracture. As a result of the combined impact, the impact toughness of the steel improved after cryogenic treatment.

The results of wear topography show that cryogenic treatment can reduce adhesive wear, which has been reported in some research $[9,57]$. In the research, the reduction of adhesive wear was attributed to increased hardness. In contrast, in this work, with an insignificant increase in hardness, the reduction of adhesive wear and increase of abrasive wear may be owed to the high hardness of more precipitated carbides induced by cryogenic treatment. Moreover, the presence of oxidative wear after cryogenic treatment may be due to formation of oxide films at localized risen temperature caused by frictional heat during dry sliding [58].

Although cryogenic treatment can improve both wear resistance and impact toughness of $42 \mathrm{CrMo}$ steel, the effect of parameters of cryogenic treatment on wear resistance is different from that on impact toughness. In order to obtain a good combination of improvements of these two mechanical properties, multiobjective optimization can be conducted using traditional or intelligent optimization algorithms in a future study.

\section{Conclusions}

This work investigated the effect of cyclic cryogenic treatment with different parameters on wear resistance and impact toughness of $42 \mathrm{CrMo}$ steel and optimization of the parameters by using the orthogonal design method and range analysis. Wear mechanism and fracture mechanism were analyzed by examining wear topography and fracture topography using SEM. Moreover, the influencing mechanism of cryogenic treatment on wear resistance and impact toughness was also studied by analyzing microstructures with SEM. The main conclusions obtained from these analyses are as follows:

(1) Cryogenic treatment has insignificant effect on hardness of hardened $42 \mathrm{CrMo}$ steel, which can be ascribed to combination of little transformation of retained austenite into martensite and the adverse impact of lowered carbon content in martensite.

(2) Cryogenic treatment can significantly improve wear resistance of $42 \mathrm{CrMo}$ steel, whose changing trend is consistent with that of COF. For improving the wear resistance of the steel, the most influential parameter is cryogenic temperature, followed by holding time and cycles number. The optimum values of these parameters are $-160^{\circ} \mathrm{C}, 24 \mathrm{~h}$ and two cycles. The influencing mechanism is the increased precipitation of carbides induced by cryogenic treatment, and the carbide precipitation increases with lowering cryogenic temperature or extending holding time.

(3) Cryogenic treatment can also significantly improve the impact toughness of $42 \mathrm{CrMo}$ steel. The most influential parameter for improving the impact toughness of the steel is holding time, followed by cycles number and cryogenic temperature. The optimum values of the parameters for improving impact toughness are $-120^{\circ} \mathrm{C}, 24 \mathrm{~h}$ and three cycles. The influencing mechanism may be the increased precipitation of carbides induced by cryogenic treatment.

(4) The wear mechanism of CT is the combination of abrasive wear and adhesive wear with oxidative wear, whereas the dominant wear mechanism of CHT is adhesive wear. The adhesive wear is reduced after CT compared with CHT.

(5) The fracture mechanism of CT and CHT is quasicleavage fracture, and quasicleavage fracture increases after CT compared with CHT, which is in accordance with the increase in impact toughness after cryogenic treatment.

\section{Data Availability}

The data used to support the findings of this work are included within the article. 


\section{Conflicts of Interest}

The authors declare that there are no conflicts of interest regarding the publication of this article.

\section{Acknowledgments}

This work was supported by the National Natural Science Foundation of China (Grant no. 51675363).

\section{References}

[1] H. Ji, H. Duan, Y. Li et al., "Optimization the working parameters of as-forged 42CrMo steel by constitutive equationdynamic recrystallization equation and processing maps," Journal of Materials Research and Technology, vol. 9, no. 4, pp. 7210-7224, 2020.

[2] Z. X. Zhao, Materials for Mechanical Engineering, Xidian University Press, Xi'an, China, 2016, in Chinese.

[3] D. Jandová, P. Šuchmann, J. Nižňanská et al., "Microstructure of tool steel X37CrMoV5 after cryogenic treatment and its effect on wear resistance," Key Engineering Materials, vol. 647, pp. 23-37, 2015.

[4] R. Sola, P. Veronesi, R. Giovanardi et al., "Effect of heat treatment before cryogenic cooling on the proprieties of AISI M2 steel," Metallurgia Italiana, vol. 109, no. 10, pp. 5-16, 2017.

[5] S. Kumar, N. K. Khedkar, B. Jagtap et al., "The effects of cryogenic treatment on cutting tools," IOP Conference Series: Materials Science and Engineering, vol. 225, no. 1, Article ID 012104, 2017.

[6] R. Uhlař, L. M. Hlavac, L. Gembalova et al., "Abrasive water jet cutting of the steels samples cooled by liquid nitrogen," Applied Mechanics and Materials, vol. 308, pp. 7-12, 2013.

[7] M. C. A. Dumasia, V. A. Kulkarni, and M. K. Sonar, "A review on the effect of cryogenic treatment on metals," International Research Journal of Engineering and Technology, vol. 4, pp. 2402-2406, 2017.

[8] S. Kumar, M. Nagaraj, N. K. Khedkar, and A. Bongale, "Influence of deep cryogenic treatment on dry sliding wear behaviour of AISI D3 die steel," Materials Research Express, vol. 5, no. 11, p. 116525, 2018.

[9] J. Soleimany, H. Ghayour, K. Amini et al., "The effect of deep cryogenic treatment on microstructure and wear behavior of H11 tool steel," Physics of Metals and Metallography, vol. 120, no. 9, pp. 888-897, 2019.

[10] G. Prieto and W. R. Tuckart, "Influence of cryogenic treatments on the wear behavior of AISI 420 martensitic stainless steel," Journal of Materials Engineering and Performance, vol. 26, no. 11, pp. 5262-5271, 2017.

[11] V. Varghese, M. R. Ramesh, D. Chakradhar et al., "Influence of deep cryogenic treatment on performance of cemented carbide (WC-Co) inserts during dry end milling of maraging steel," Journal of Manufacturing Processes, vol. 37, pp. 242250, 2019.

[12] W. Gao, X. Wang, J. Chen, C. Ban, J. Cui, and Z. Lu, "Influence of deep cryogenic treatment on microstructure and properties of 7A99 ultra-high strength aluminum alloy," Metals, vol. 9, no. 6, p. 631, 2019.

[13] W. Guo, R. Yamada, J. Saida et al., "Rejuvenation and plasticization of metallic glass by deep cryogenic cycling treatment," Intermetallics, vol. 93, pp. 141-147, 2018.

[14] H. J. Ni, L. Zhuo, H. Gu et al., "Effect of cryogenic treatment on micro-structure and properties of different polymer materials," MATEC Web of Conferences, vol. 166, no. 2, Article ID 01002, 2018.

[15] W. Chen, W. Wu, C. Li, and X. Meng, "Influence of deep cryogenic treatment and secondary tempering on microstructure and mechanical properties of medium-carbon low-alloy steels," Journal of Materials Engineering and Performance, vol. 29, no. 1, pp. 10-22, 2020.

[16] R. Sola, G. Poli, S. Defanti et al., "Effect of deep cryogenic treatment on the properties of AISI M2 steel," in Proceedings of the European Conference on Heat Treatment 2015 and 22nd Heat Treatment and Surface Engineering from Tradition to Innovation Congress, Associazione Italiana di Metallurgia, Venezia, Italy, May 2015.

[17] R. Sola, P. Veronesi, R. Giovanardi et al., "Influence of a posttempering cryogenic treatment on the toughness of the AISI M2 steel," in Proceedings of the 7th International Congress on Science and Technology of Steelmaking (ICS 2018), Associazione Italiana Di Metallurgia, Venice, Italy, June 2018.

[18] R. Sola, R. Giovanardi, G. Parigi, and P. Veronesi, "A novel methods for fracture toughness evaluation of tool steels with post-tempering cryogenic treatment," Metals, vol. 7, no. 3, p. 75, 2017.

[19] D. A. College and Y. Zhu, "Alleviating surface tensile stress in e-beam treated tool steels by cryogenic treatment," Materials Science and Engineering: A, vol. 722, pp. 167-172, 2018.

[20] K. Menderes and H. Saruhan, "Derin kriyojenik işlemin farklı Bekletme Sürelerinin AISI 4140 (42CrMo4) Çeliğin Mekanik Özelliklerine etkisi," Düzce Üniversitesi Bilim Ve Teknoloji Dergisi, vol. 6, no. 3, pp. 553-564, 2018.

[21] D. Senthilkumar and I. Rajendran, "Optimization of deep cryogenic treatment to reduce wear loss of 4140 steel," Materials and Manufacturing Processes, vol. 27, no. 5, pp. 567-572, 2012.

[22] D. Senthilkumar, I. Rajendran, and M. Pellizzari, "Effect of cryogenic treatment on the hardness and tensile behaviour of AISI 4140 steel," International Journal of Microstructure and Materials Properties, vol. 6, no. 5, p. 366, 2011.

[23] D. Senthilkumar, I. Rajendran, M. Pellizzari, and J. Siiriainen, "Influence of shallow and deep cryogenic treatment on the residual state of stress of 4140 steel," Journal of Materials Processing Technology, vol. 211, no. 3, pp. 396-401, 2011.

[24] G. Höke, I. Şahin, H. Çinici, and T. Findik, "Effect of cryogenic processes on the mechanical properties of SAE 4140 steel," Journal of Selcuk-Technic, vol. 13, pp. 25-37, 2014.

[25] I. Sahin, G. Höke, H. Çinici, T. Findik, H. Koralay, and U. Arabaci, "Effects of subzero treatments on the mechanical properties of the SAE 4140 steel," Materiali in Tehnologije, vol. 53, no. 4, pp. 489-494, 2019.

[26] A. R. Jamali, W. Khan, A. D. Chandio et al., "Effect of cryogenic treatment on mechanical properties of AISI 4340 and AISI 4140 steel," Mehran University Research Journal of Engineering and Technology, vol. 38, no. 3, pp. 755-766, 2019.

[27] Z. X. Ding and Y. Tian, Marine Machinery Repair Technology, Wuhan University of Technology Press, Wuhan, China, 2013, in Chinese.

[28] S. Talebi, H. Ghasemi-Nanesa, M. Jahazi, and H. Melkonyan, "In situ study of phase transformations during non-isothermal tempering of bainitic and martensitic microstructures," Metals, vol. 7, no. 9, p. 346, 2017.

[29] N. Pillai, R. Karthikeyan, and J. P. Davim, "A review on effects of cryogenic treatment of aisi'd'series cold working tool steels," Reviews on Advanced Materials Science, vol. 51, no. 2, pp. 149-159, 2017.

[30] A. Razavykia, C. Delprete, and P. Baldissera, "Correlation between microstructural alteration, mechanical properties 
and manufacturability after cryogenic treatment: a review," Materials, vol. 12, no. 20, p. 3302, 2019.

[31] K. Amini, A. Akhbarizadeh, and S. Javadpour, "Cryogenic heat treatment of the ferrous materials-a review of the current state," Metallurgical Research \& Technology, vol. 113, no. 6, p. 611, 2016.

[32] D. N. Collins and J. Dormer, "Deep cryogenic treatment of a D2 cold work tool steels," Heat Treatment of Metals, vol. 24, no. 3, pp. 71-74, 1997.

[33] S. Zhirafar, A. Rezaeian, and M. Pugh, "Effect of cryogenic treatment on the mechanical properties of 4340 steel," Journal of Materials Processing Technology, vol. 186, no. 1-3, pp. 298-303, 2007.

[34] M. A. Jaswin, D. M. Lal, and A. Rajadurai, "Effect of cryogenic treatment on the microstructure and wear resistance of $\mathrm{X} 45 \mathrm{Cr} 9 \mathrm{Si} 3$ and $\mathrm{X} 53 \mathrm{Cr} 22 \mathrm{Mn} 9 \mathrm{Ni} 4 \mathrm{~N}$ valve steels," Tribology Transactions, vol. 54, no. 3, pp. 341-350, 2011.

[35] S. S. Gill, J. Singh, R. Singh, and H. Singh, "Effect of cryogenic treatment on AISI M2 high speed steel: metallurgical and mechanical characterization," Journal of Materials Engineering and Performance, vol. 21, no. 7, pp. 1320-1326, 2012.

[36] X. G. Yan and D. Y. Li, "Effects of the sub-zero treatment condition on microstructure, mechanical behavior and wear resistance of W9Mo3Cr4V high speed steel," Wear, vol. 302, no. 1-2, pp. 854-862, 2013.

[37] W. Zhao, X. L. Yue, H. M. Chen, and K. Qin, "Prediction of mechanical properties of $42 \mathrm{CrMo}$ steel after quenching and tempering treatment," Heat Treatment of Metals, vol. 42, no. 7, pp. 158-162, 2017, in Chinese.

[38] S. Harish, A. Bensely, D. Mohan Lal, A. Rajadurai, and G. B. Lenkey, "Microstructural study of cryogenically treated En 31 bearing steel," Journal of Materials Processing Technology, vol. 209, no. 7, pp. 3351-3357, 2009.

[39] A. Ciski, "Deep cryogenic treatment and tempering at different temperatures of HS6-5-2 high speed steel," Archives of Metallurgy and Materials, vol. 63, no. 2, pp. 929-934, 2018.

[40] J. D. Darwin, D. M. Lal, and G. Nagarajan, "Optimization of cryogenic treatment to maximize the wear resistance of $18 \%$ Cr martensitic stainless steel by taguchi method," Journal of Materials Processing Technology, vol. 195, no. 1-3, pp. 241-247, 2008.

[41] T. Shinde, "Influence of carbide particle size on the wear performance of cryogenically treated H13 die steel," Surface Engineering, pp. 1-9, 2020.

[42] P. Jimbert, M. Iturrondobeitia, J. Ibarretxe, and R. FernandezMartinez, "Influence of cryogenic treatment on wear resistance and microstructure of AISI A8 tool steel," Metals, vol. 8, no. 12, p. 1038, 2018.

[43] S. Kumar, M. Nagraj, A. Bongale, and N. Khedkar, "Deep cryogenic treatment of AISI M2 tool steel and optimisation of its wear characteristics using taguchi's approach," Arabian Journal for Science and Engineering, vol. 43, no. 9, pp. 49174929, 2018.

[44] J. Li, X. Yan, X. Liang, H. Guo, and D. Y. Li, "Influence of different cryogenic treatments on high-temperature wear behavior of M2 steel," Wear, vol. 376-377, pp. 1112-1121, 2017.

[45] Y. Yao and Y. Zhou, "Effects of deep cryogenic treatment on wear resistance and structure of GB 35CrMoV steel," Metals, vol. 8 , no. 7 , p. $502,2018$.

[46] A. Akhbarizadeh, A. Shafyei, and M. A. Golozar, "Effects of cryogenic treatment on wear behavior of D6 tool steel," Materials \& Design, vol. 30, no. 8, pp. 3259-3264, 2009.
[47] A. Akhbarizadeh, S. Javadpour, and K. Amini, "Investigating the effect of electric current flow on the wear behavior of 1.2080 tool steel during the deep cryogenic heat treatment," Materials \& Design, vol. 45, pp. 103-109, 2013.

[48] L. Bhaskar and D. S. Raj, "Evaluation of the effect of cryogenic treatment of HSS drills at different holding time in drilling AISI 316-SS," Engineering Research Express, vol. 2, no. 2, Article ID 025005, 2020.

[49] I. Gunes, A. Cicek, K. Aslantas, and F. Kara, "Effect of deep cryogenic treatment on wear resistance of AISI 52100 bearing steel," Transactions of the Indian Institute of Metals, vol. 67, no. 6, pp. 909-917, 2014.

[50] S. Li, N. Min, J. Li, X. Wu, C. Li, and L. Tang, "Experimental verification of segregation of carbon and precipitation of carbides due to deep cryogenic treatment for tool steel by internal friction method," Materials Science and Engineering: $A$, vol. 575, pp. 51-60, 2013.

[51] S. Li and X. Wu, "Microstructural evolution and corresponding property changes after deep cryotreatment of tool steel," Materials Science and Technology, vol. 31, no. 15, pp. 1867-1878, 2015.

[52] V. G. Gavriljuk, V. A. Sirosh, Y. N. Petrov, A. I. Tyshchenko, W. Theisen, and A. Kortmann, "Carbide precipitation during tempering of a tool steel subjected to deep cryogenic treatment," Metallurgical and Materials Transactions A, vol. 45, no. 5, pp. 2453-2465, 2014.

[53] X. Xie, X. C. Wu, and N. Min, "Carbon Segregation Behavior of high carbon high-alloy steel during deep cryogenic treatment using 3DAP," Acta Metallurgica Sinica, vol. 51, no. 3, pp. 325-332, 2015, in Chinese.

[54] Y. Xiao, W. Li, H. S. Zhao, X. W. Lu, and X. J. Jin, "Investigation of carbon segregation during low temperature tempering in a medium carbon steel," Materials Characterization, vol. 117, pp. 84-90, 2016.

[55] C. L. Israel, P. H. S. Cardoso, M. B. Da Silva et al., "Effects of deep cryogenic treatment on microstructure, impact toughness and wear resistance of an AISI D6 tool steel," Wear, vol. 456-457, Article ID 203382, 2020.

[56] Z. Weng, K. Gu, K. Wang, X. Liu, and J. Wang, "The reinforcement role of deep cryogenic treatment on the strength and toughness of alloy structural steel," Materials Science and Engineering: A, vol. 772, Article ID 138698, 2020.

[57] K. Amini, M. Negahbani, and H. G. K. Amini, "The effect of deep cryogenic treatment on hardness and wear behavior of the H13 tool steel," La Metallurgia Italiana, vol. 107, no. 3, pp. 53-58, 2015.

[58] H. Paydar, K. Amini, and A. Akhbarizadeh, "Investigating the effect of deep cryogenic heat treatment on the wear behaviour of $100 \mathrm{Cr} 6$ alloy steel," Kovove Materialy, vol. 52, no. 3, pp. 163-169, 2014. 